\title{
Superparamagnetic Iron Oxide Nanoparticles and Static Magnetic Field Regulate Neural Stem Cell Proliferation
}

OPEN ACCESS

Edited by:

Zuhong He,

Wuhan University, China

Reviewed by:

Wenli Chen,

South China Normal University, China

Fang Yang,

Southeast University, China

Xiaowei Yang,

Tongji University, China

Guangli Suo,

Suzhou Institute of Nano-Tech and Nano-Bionics, Chinese Academy

of Sciences (CAS), China

*Correspondence:

Renjie Chai

renjiec@seu.edu.cn

Mingliang Tang

mltang@suda.edu.cn

†These authors have contributed equally to this work

Specialty section:

This article was submitted to Cellular Neuropathology,

a section of the journal

Frontiers in Cellular Neuroscience

Received: 15 November 2021 Accepted: 31 December 2021 Published: 04 February 2022

Citation:

Li D, Hu Y, Wei H, Chen W, Liu Y, Yan X, Guo L, Liao M, Chen B, Chai R and Tang $M(2022)$

Superparamagnetic Iron Oxide Nanoparticles and Static Magnetic Field Regulate Neural Stem Cell Proliferation.

Front. Cell. Neurosci. 15:815280. doi: 10.3389/fncel.2021.815280

\begin{abstract}
Dan $\mathrm{Li}^{1,2,3+}$, Yangnan $\mathrm{Hu}^{2,3 \dagger}$, Hao Wei ${ }^{4+}$, Wei Chen ${ }^{2,3}$, Yun Liu ${ }^{2,3}$, Xiaoqian Yann, Lingna Guo ${ }^{2,3,5}$, Menghui Liao ${ }^{2,3}$, Bo Chen ${ }^{6}$, Renjie Chai ${ }^{2,3 *}$ and Mingliang Tang ${ }^{2,7 *}$

${ }^{1}$ School of Biology, Food and Environment, Hefei University, Hefei, China, ${ }^{2}$ Co-innovation Center of Neuroregeneration, Nantong University, Nantong, China, ${ }^{3}$ School of Life Sciences and Technology, Southeast University, Nanjing, China, ${ }^{4}$ Department of Otorhinolaryngology Head and Neck Surgery, Drum Tower Clinical Medical College, Nanjing Medical University, Nanjing, China, ${ }^{5}$ Department of Otolaryngology Head and Neck Surgery, The Second Affiliated Hospital of Anhui Medical University, Hefei, China, ${ }^{6}$ Materials Science and Devices Institute, Suzhou University of Science and Technology, Suzhou, China, ${ }^{7}$ Department of Cardiovascular Surgery of the First Affiliated Hospital and Institute for Cardiovascular Science, Medical College, Soochow University, Suzhou, China
\end{abstract}

Neural stem cells (NSCs) transplantation is a promising approach for the treatment of various neurodegenerative diseases. Superparamagnetic iron oxide nanoparticles (SPIOs) are reported to modulate stem cell behaviors and are used for medical imaging. However, the detailed effects of SPIOs under the presence of static magnetic field (SMF) on NSCs are not well elucidated. In this study, it was found that SPIOs could enter the cells within $24 \mathrm{~h}$, while they were mainly distributed in the lysosomes. SPIO exhibited good adhesion and excellent biocompatibility at concentrations below $500 \mu \mathrm{g} / \mathrm{ml}$. In addition, SPIOs were able to promote NSC proliferation in the absence of SMF. In contrast, the high intensity of SMF (145 $\pm 10 \mathrm{mT}$ ) inhibited the expansion ability of NSCs. Our results demonstrate that SPIOs with SMF could promote NSC proliferation, which could have profound significance for tissue engineering and regenerative medicine for SPIO applications.

Keywords: SPIO, SMF, neural stem cells, proliferation, regulation

\section{INTRODUCTION}

Neural stem cells (NSCs) act as one of the adult stem cells that are typically considered capable of giving rise to neurons and glia cell lineages (Gage, 2000). Currently, they have been widely used for spinal cord repairing and for the treatment of various neurodegenerative diseases in animal models (Gage, 2000; Madhavan and Collier, 2010; Mathieu et al., 2010; Carletti et al., 2011; Yoneyama et al., 2011; He et al., 2012; Reekmans et al., 2012). Nowadays, numerous reports have suggested that biomaterials could provide a tremendous opportunity to influence stem cell behaviors. For instance, the physicochemical properties of biomaterials, including substrate mechanical stiffness (Engler et al., 2006; Lee et al., 2013), nanometer-scale topography (Dalby et al., 2007; Yim et al., 2010; McMurray et al., 2011), and simple chemical functionality (Benoit et al., 2008; Saha et al., 2011), could regulate the stem cell fate. In particular, a previous study has shown that superparamagnetic iron oxide nanoparticles (SPIOs) promoted the proliferation of human mesenchymal stem cells (MSCs) through diminishing intracellular $\mathrm{H}_{2} \mathrm{O}_{2}$ and accelerating cell cycle progression (Huang et al., 2009). Furthermore, recent research has indicated that SPIOs promoted 
osteogenic differentiation of human bone-derived mesenchymal stem cells (hBMSCs) (Wang et al., 2016). Similarly, it has also been reported that SPIOs could promote osteogenic differentiation of adipose-derived mesenchymal stem cells (ASCs) (Xiao et al., 2015). These findings suggest that SPIOs may have the potential to modulate stem cell behaviors.

Stem cell fate is determined by the complex interactions between stem cells and their surroundings, including biochemical factors, extracellular matrix components, intercellular interactions, and physical factors (Allazetta and Lutolf, 2015). A magnetic field is an effective physical factor that has been reported to modulate cell proliferation as earlier as 1999 (Fanelli et al., 1999). Meanwhile, it was reported to mediate the osteogenic differentiation of human ASCs (Kang et al., 2013) and induce MSC differentiation into osteoblasts and cartilage (Ross et al., 2015). In addition, the magnetic fields and magnetic nanomaterials were used together to induce the growth direction of neurons (Riggio et al., 2014) and facilitate drug delivery (Qiu et al., 2017). However, there is no report to explore the biological effects of SPIO under the presence of a magnetic field on NSC behaviors.

\section{MATERIALS AND METHODS}

\section{Synthesis of Superparamagnetic Iron Oxide Nanoparticles}

The SPIOs were coated by polyglucose-sorbitolcarboxymethylether (PSC) as modified in this experiment. The method to synthesize SPIOs was applied to the classic chemical coprecipitation combined with an excellent alternatingcurrent magnetic field (ACMF)-induced internal-heat mode (Chen et al., 2016). Briefly, $40 \mathrm{mg}$ PSC was dissolved in $2 \mathrm{ml}$ of deionized water, then the mixture of the $6 \mathrm{mg} \mathrm{FeCl}_{3}$ with $3 \mathrm{mg}$ $\mathrm{FeCl}_{2}$ dissolved in $15 \mathrm{ml}$ of deionized water was added. After cooling the mixture to $5^{\circ} \mathrm{C}, 1 \mathrm{~g} 28 \%(\mathrm{w} / \mathrm{v})$ ammonium hydroxide was added with stirring for over $2 \mathrm{~min}$. The mixture was then heated at $80^{\circ} \mathrm{C}$ for $1 \mathrm{~h}$, then the deionized water was purified with five cycles of ultrafiltration using a $100 \mathrm{kDa}$ membrane.

\section{Characterization of Superparamagnetic Iron Oxide Nanoparticles}

The core of synthesized SPIOs was detected by transmission electron microscopy (TEM; JEOL/JEM-200CX, Japan). The size distribution was analyzed by dynamic light scattering (DLS) with a particle size analyzer (Malvern Zetasizer Nano ZS90, United Kingdom). The hysteresis loop of SPIOs was measured using a vibrating sample magnetometer (LS 7307-9309, Lakeshore Cryotronic, United States). The final concentrations of iron in the aqueous solution were measured by inductively coupled plasma mass spectrometry (ICP-MS) on an Optima 5300DV instrument.

\section{Neural Stem Cell Culture}

Neural stem cell isolation and culture were described in the previously published protocol [32]. Briefly, NSCs were cultured in mixed DMEM-F12 medium (Gibco, Grand Island, NY) containing 2\% B-27 (Gibco), $100 \mathrm{U} / \mathrm{ml}$ penicillin, and $100 \mu \mathrm{g} / \mathrm{ml}$ streptomycin (Sigma-Aldrich, St. Louis, MO, United States) in the condition of $5 \% \mathrm{CO}_{2}$ at $37^{\circ} \mathrm{C}$. NSCs were passaged every 3-5 days during culturing. For the determination of NSC proliferation, cells were seeded with a concentration of $5 \times 10^{4}$ cells/ml in DMEM-F12 medium with 2\% B-27, $20 \mathrm{ng} / \mathrm{ml} \mathrm{EGF}$ (R\&D Systems, Minneapolis, MN, United States), and $20 \mathrm{ng} / \mathrm{ml}$ FGF-2 (R\&D Systems, Minneapolis, MN, United States). For NSC differentiation assays, cells were seeded in an NSC differentiation kit (Stem Cell, Hangzhou, China). The care and use of animals in these experiments followed the guidelines and protocol approved by the Care and Use of Animals Committee of Southeast University. All efforts were made to minimize the number of animals used and their suffering.

\section{Cellular Uptake of Superparamagnetic Iron Oxide Nanoparticles by Inductively Coupled Plasma Mass Spectrometry}

Cells were seeded in $25 \mathrm{~cm}^{2}$ flasks at the concentration of $1 \times 10^{5}$ to $1 \times 10^{6}$ per flask and incubated with SPIOs at the indicated concentrations. After 1, 2, 3, or 4 days of treatment, cells were harvested and counted. Then, the cell suspension was dissociated by hydrochloric acid with a final concentration of $60 \%$. The concentration of iron in cell lysates was measured by ICP-MS according to PerkinElmer's operating procedures.

\section{Cell Viability Assay}

Neural stem cells were seeded in 96-well cell culture plates at the concentration of $1 \times 10^{5}$ cells per well $(n=6)$ and cultured overnight. The cells were then incubated with differentiation concentrations of SPIOs at indicated concentrations. After culturing for 12 or $24 \mathrm{~h}$, cell viability was measured by CCK-8 assay (Beyotime, Shanghai, China) according to the manufacturer's instructions. The NSCs cultured with the ordinary medium were considered as the control.

\section{Immunostaining}

Neural stem cells were fixed with $4 \%$ paraformaldehyde for $1 \mathrm{~h}$ at room temperature, following treatment with blocking medium for $1 \mathrm{~h}$. Next, the cells were incubated with primary antibody diluted solution overnight at $4^{\circ} \mathrm{C}$. Then, each sample was washed with phosphate buffer solution $[0.1 \%$ Triton $\mathrm{X}$ 100 in phosphate buffer solution (PBST) twice per $5 \mathrm{~min}]$. The samples were further incubated with a secondary antibody for $1 \mathrm{~h}$ at room temperature. Finally, samples were washed with PBST, and an antifade fluorescence mounting medium (DAKO) was added. The antibodies used were Nestin (Beyotime, China). Cell proliferation was detected by Click-it EdU imaging kit (Invitrogen). All the images were captured by a Zeiss LSM 700 confocal microscope, and Image (NIH) was used for image analysis.

\section{Scanning Electron Microscope and Transmission Electron Microscopy Examination}

Neural stem cells were seeded in 24-well cell culture plates at the concentration of $1 \times 10^{4}$ cells per well and incubated 
A

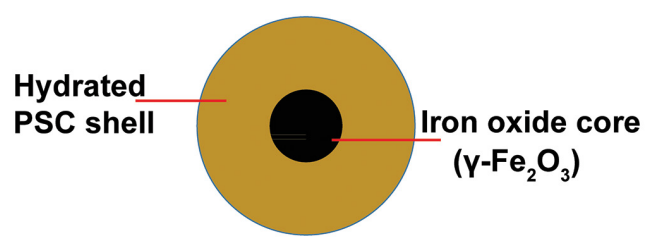

C

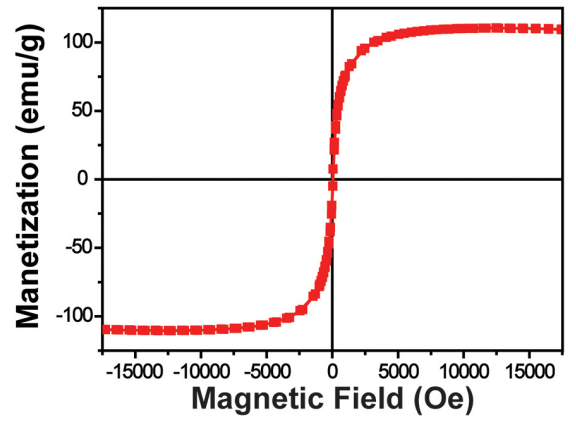

B

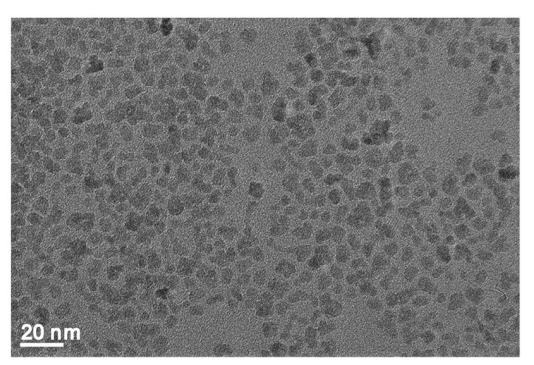

D

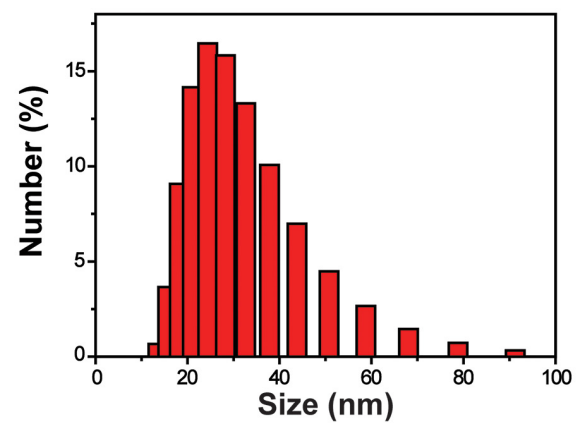

FIGURE 1 | Characterization of SPIOs. (A) Schematic structure of SPIOs. (B) TEM image of SPIOs. (C) Hysteresis loop of SPIOs. (D) Particle size distributions of the SPIOs as measured by DLS.

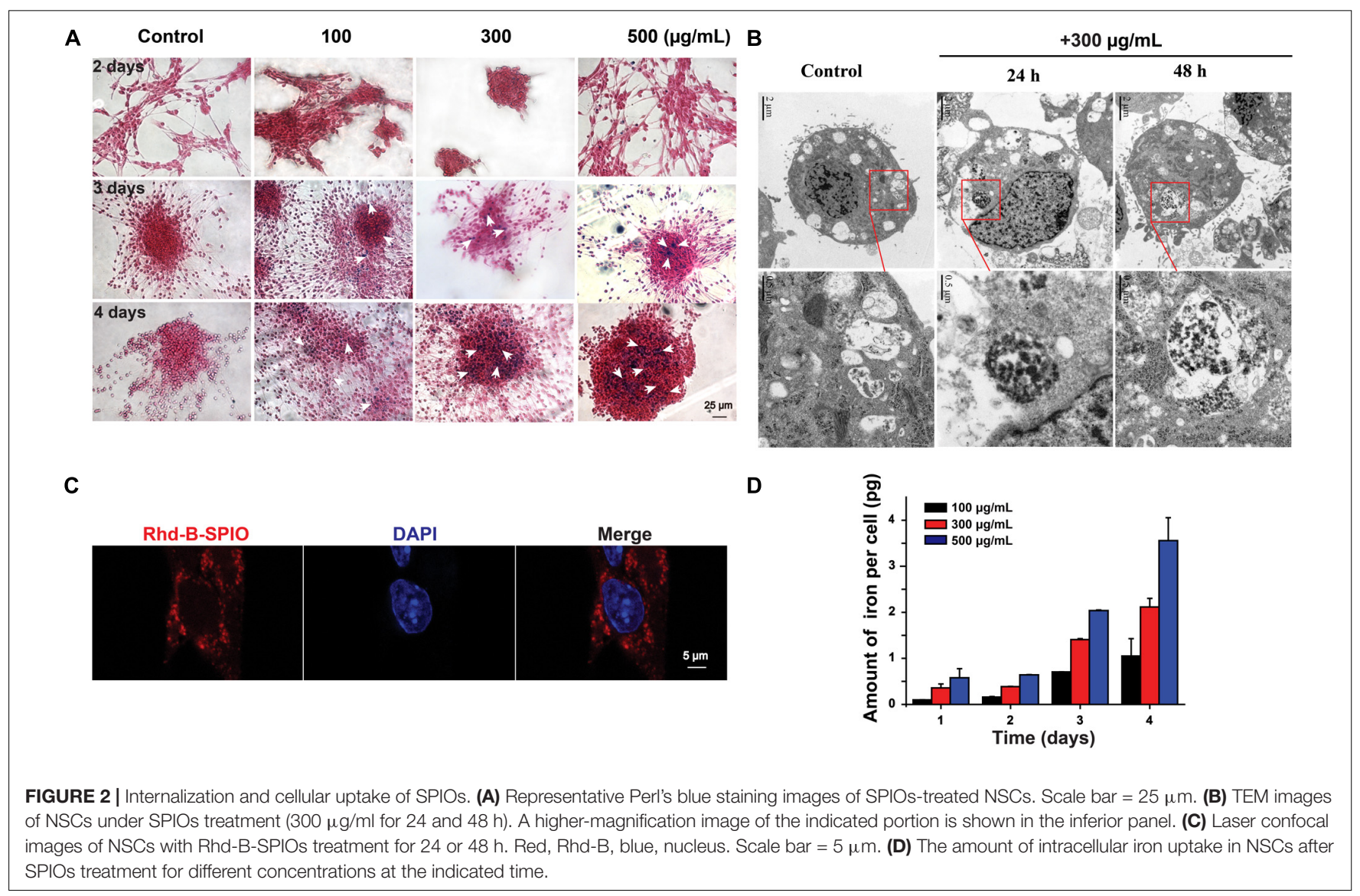


with a differentiation concentration of SPIOs at indicated concentrations. After incubation for 3 days, cells were washed two times with $1 \times \mathrm{PBS}$ ( $\mathrm{pH} 7.4) ; 2.5 \%$ glutaraldehyde solution (Alfa Aesar, Tewksbury, MA, United States) was added to each sample. Cells were co-incubated for $1 \mathrm{~h}$ at $37^{\circ} \mathrm{C}$. Then, cells were dehydrated overnight, and the cell morphology was detected by scanning electron microscope (SEM) (Ultra Plus, Zeiss, Oberkochen, Germany).

Neural stem cells were seeded in $25 \mathrm{~cm}^{2}$ flasks at the concentration of $1 \times 10^{6}$ and incubated with SPIOs at the concentration of $100 \mu \mathrm{g} / \mathrm{ml}$. After 12- or 24-h treatment, the cells were harvested and washed two times with PBS; $2.5 \%$ glutaraldehyde solution was added to each sample, and cells were co-incubated overnight at $4^{\circ} \mathrm{C}$ to fix the cells. Then, the samples were transferred to $1 \%$ osmium tetroxide, dehydrated in ethanol, and embedded in Epon (Sigma-Aldrich). Finally, uranyl acetate and lead citrate were used for staining of ultrathin slices (60$80 \mathrm{~nm}$ ). The images were captured by TEM (JEOL/JEM-200CX, Tokyo, Japan).

\section{Statistical Analysis}

All data are shown as mean and SD. Statistical analyses were conducted using GraphPad Prism 6 software. For all experiments, $n$ represents the number of replicates, and at least three individual experiments were conducted. One- or two-way ANOVA analysis followed by a Tukey's post hoc test was used to determine the statistical significance between multiple groups, and Student's $t$-test was used for comparisons between two groups. A value of $p<0.05$ was considered to be statistically significant.

\section{RESULTS}

\section{Synthesis and Characterization of Superparamagnetic Iron Oxide Nanoparticles}

The SPIOs were composed of a $\gamma-\mathrm{Fe}_{2} \mathrm{O}_{3}$ core and PSC shell (Figure 1A). The size of the $\gamma-\mathrm{Fe}_{2} \mathrm{O}_{3}$ core is about 6$8 \mathrm{~nm}$ (Figure 1B). The hysteresis loop of SPIOs is about $105 \mathrm{emu} / \mathrm{g}$ (Figure 1C), which indicates that it has a good superparamagnetic property. The average diameter of whole SPIOs measured by DLS is about $30 \mathrm{~nm}$ (Figure 1D). These results suggest that the SPIOs synthesized by this method have a uniform particle size, stable structure, good dispersion (PDI of 0.154 ), and stronger magnetic properties than the conventional coprecipitation method.

\section{Internalization and Cellular Uptake of Superparamagnetic Iron Oxide Nanoparticles}

Superparamagnetic iron oxide could enter the cells after coincubation for 1 day (Figure 2A). The amount of SPIO could

\section{A}

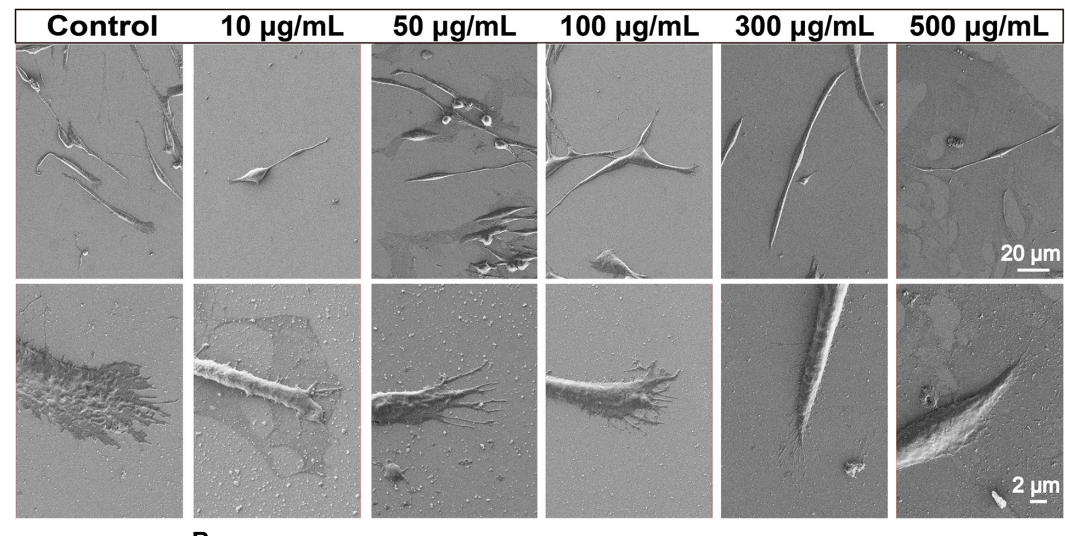

B

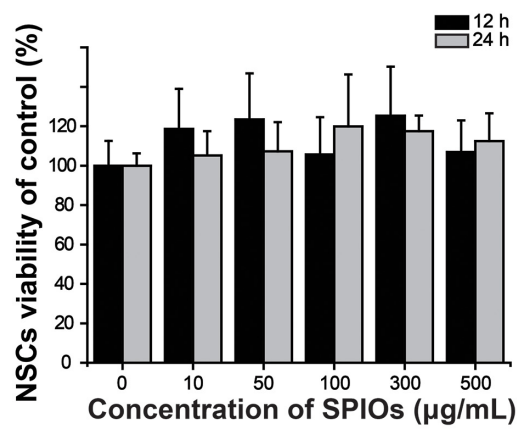

FIGURE 3 | Biocompatibility of SPIOs. (A) SEM images of NSCs after culturing with SPIO for 3 days at indicated concentrations. (B) Cell viability was detected by the CCK-8 assay. The cells were treated with SPIOs for 12-24 h at indicated concentrations. Data were normalized to the control group (no SPIOs exposure). Data are presented as mean $\pm \mathrm{SD}$. Student's $t$-test. 
increase with time and concentrations of SPIO (Figure 2D). It was noticed that there was no significant difference between the 3 - and 4-day groups, indicating that the uptake by a single cell was stale within 3 days. Furthermore, TEM and fluorescence imaging were employed to examine the internalization of SPIOs in NSCs. TEM results revealed that SPIOs were located in the lysosomes after 24 and 48 h of exposure (Figure 2B). It was further verified that SPIOs were located outside the cell nucleus after $24 \mathrm{~h}$ of exposure (Figure 2C).

The morphology of NSCs was observed by SEM after 3-day co-incubation with various concentrations of SPIOs. Cells in all groups presented normal phenotypes (Figure 3A). Importantly, SPIOs exposure did not affect NSC viability at concentrations up to $500 \mu \mathrm{g} / \mathrm{ml}$ for $24 \mathrm{~h}$ (Figure 3B), indicating the good biocompatibility of SPIOs.

\section{Effects of Superparamagnetic Iron Oxide Nanoparticle and Static Magnetic Field on Neural Stem Cell Proliferation}

Neural stem cell proliferation was first evaluated by neurosphere formation assay. NSCs from higher concentrations of SPIOs (300 and $500 \mu \mathrm{g} / \mathrm{ml}$ ) had a significantly higher rate of neurosphere formation compared to the control group, while lower concentrations of SPIOs $(10,50$, and $100 \mu \mathrm{g} / \mathrm{ml})$ or $50 \pm 10 \mathrm{mT}$ SMF treatment had no obvious effect on the number of neurosphere formation (Figures 4A,B). In contrast, SPIOs at different concentrations $(100,300$, and $500 \mu \mathrm{g} / \mathrm{ml})$ simultaneously exposed to $\operatorname{SMF}(50 \pm 10 \mathrm{mT})$ resulted in a slower rate of neurosphere formation (Figures 4A,B). Although more neurospheres were generated from NSCs treated with higher concentration SPIOs, there was no significant effect on the diameters of the neurospheres compared to the control group (Figures 4A,C). Notably, when the NSCs were simultaneously exposed to SMF, the neurospheres exhibited a larger diameter at concentrations of $100-500 \mu \mathrm{g} / \mathrm{ml}$.

Since the low concentration of SPIOs (10 and $50 \mu \mathrm{g} / \mathrm{ml}$ ) had no effect on NSC proliferation regardless of SMF presence, these two concentrations were not included in the subsequent experiments. Next, EdU ${ }^{+} / \mathrm{DAPI}$ cells were counted to further examine NSC proliferation. NSCs treated with 100, 300, and $500 \mu \mathrm{g} / \mathrm{ml}$ SPIOs generated significantly more EdU ${ }^{+} / \mathrm{DAPI}$ cells than those from the control group (control group: $38.60 \pm 6.11 \%$; $100 \mu \mathrm{g} / \mathrm{ml}: 46.61 \pm 6.16 ; 300 \mu \mathrm{g} / \mathrm{ml}: 46.13 \pm 6.62 ; 500 \mu \mathrm{g} / \mathrm{ml}$ : $53.57 \pm 7.49 \%$; $p<0.001$ ) (Figures 5A,C). Furthermore, SMF $(145 \pm 10 \mathrm{mT})$ presence inhibited the ratio of $\mathrm{EdU}^{+} / \mathrm{DAPI}$ cells when compared to the control $(0 \mu \mathrm{g} / \mathrm{ml}$ : $71.62 \pm 3.93 \%$; SMF: $66.58 \pm 4.98 \% ; p<0.001)$. Next, when NSCs were cultured in the presence of SPIOs $(100,300$, and $500 \mu \mathrm{g} / \mathrm{ml})$ plus SMF $(145 \pm 10 \mathrm{mT})$ for 3 days, significantly lower ratio of EdU ${ }^{+} / \mathrm{DAPI}$ cells was observed $(100 \mu \mathrm{g} / \mathrm{ml}: 54.92 \pm 6.03 \% ; 300 \mu \mathrm{g} / \mathrm{ml}$ : $43.79 \pm 6.93 \%$; $500 \mu \mathrm{g} / \mathrm{ml}: 38.37 \pm 7.39 \%$ ) (Figures 5B,D).

Interestingly, when the SMF intensity was reduced to $50 \pm 10 \mathrm{mT}$, the exposure of SPIOs at concentrations of $100-300 \mu \mathrm{g} / \mathrm{ml}$ failed to reduce the ratio of $\mathrm{EdU}^{+} / \mathrm{DAPI}$ cells (Figures 6A,C). However, $100 \pm 10 \mathrm{mT}$ SMF could significantly

A

$0 \quad 10$

50

100

300

$500(\mu \mathrm{g} / \mathrm{mL})$
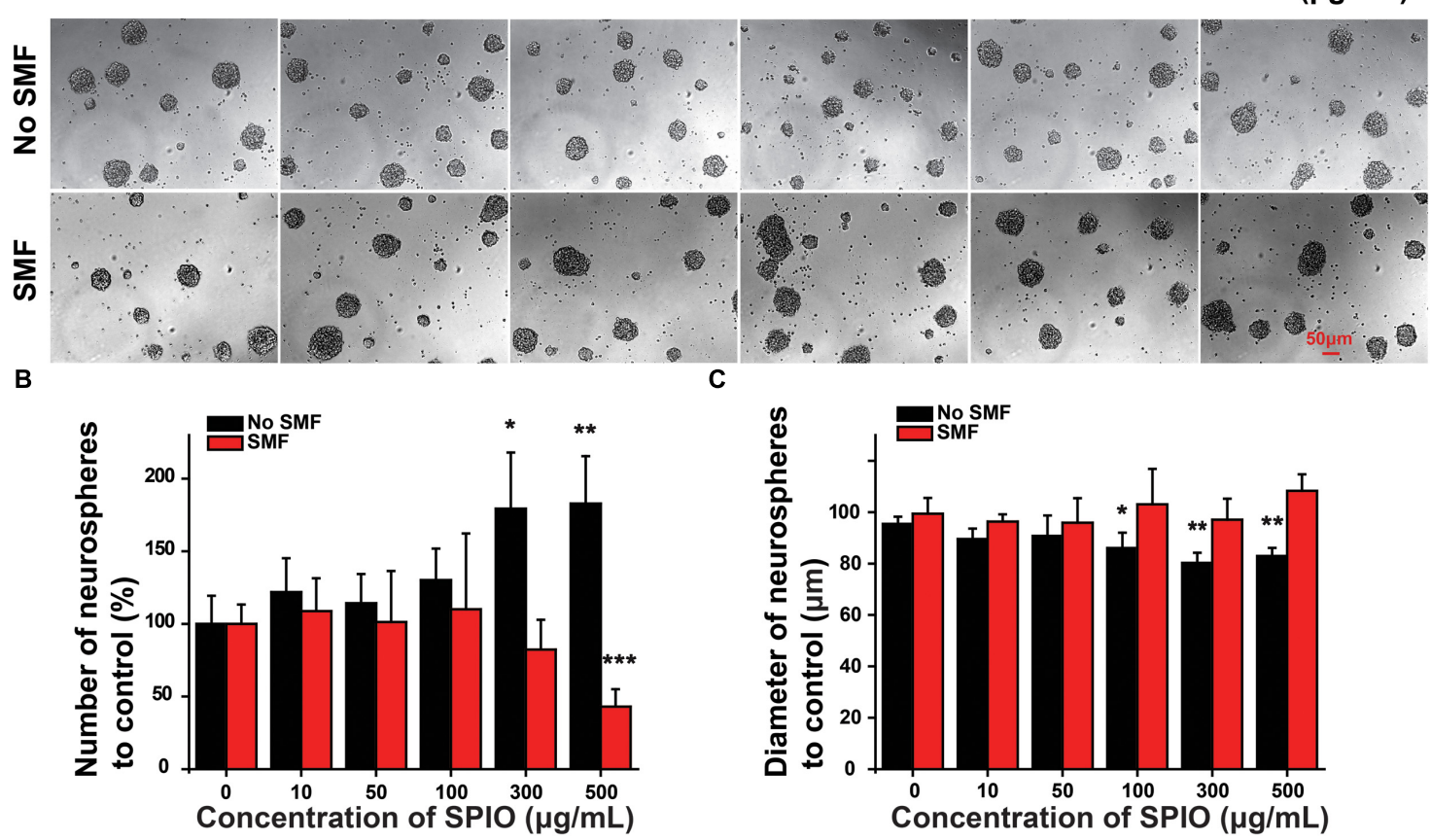

FIGURE 4 | The number and diameter of neurospheres. NSCs were cultured with indicated concentrations of SPIO (10, 50, 100, 300 , and 500 $\mu \mathrm{g} / \mathrm{ml})$ with or without SMF for 3 days. (A) Representative optical images of neurospheres. (B) Quantification of the neurospheres number. (C) Quantification of the neurospheres diameter in the experimental groups. Data are presented as mean $\pm \mathrm{SD},{ }^{\star} p<0.05,{ }^{\star \star} p<0.01$, and ${ }^{* \star *} p<0.001$. 
suppress NSC proliferation when SPIO concentration was more than $500 \mu \mathrm{g} / \mathrm{ml}$, as evidenced by the decreased ratio of $\mathrm{EdU}^{+} / \mathrm{DAPI}$ cells (Figures 6B,D).

\section{DISCUSSION}

Stem cells have a wide application prospect in the biomedical fields. NSCs have been verified for their potential in the treatment of various diseases, especially neural diseases [3-9]. The stem cell niche is the interaction between stem cells and their microenvironment which is regarded as key players in stem cell fate decisions. The niche includes several physical factors, biochemical factors, and extracellular matrix components (Allazetta and Lutolf, 2015). Many biomaterials have been proposed to modulate the stem cell niche to further regulate stem cell fate. For example, SPIOs have been reported to be able to modulate stem cell behaviors, including proliferation and differentiation (Huang et al., 2009; Xiao et al., 2015; Wang et al., 2016). Meanwhile, the magnetic field is also confirmed as one of the physical factors that affect stem cell fate decisions. In this research, we introduced SPIOs and magnetic fields together to explore whether they could affect NSC proliferation.

Some types of SPIOs have been reported to exert excellent biocompatibility, while the potential toxicity under certain conditions (e.g., surface modification) is still under debate. Numerous studies focus on SPIO cytotoxicity on different types of cells. SPIO labeling was found not to alter MSC viability and apoptosis (Schafer et al., 2009; Zhang et al., 2014; Singh et al., 2019; Xu et al., 2020). It was further revealed that SPIOs coated with unfractionated heparin did not affect MSC survival (Lee et al., 2012). Furthermore, histological examination showed that silica-coated SPIOs induced no obvious tissue impairments or abnormal inflammation and pathology in major organs (Ledda et al., 2020). Our results were consistent with the above reports that SPIOs at concentrations less than $500 \mu \mathrm{g} / \mathrm{ml}$ did not affect NSC adhesion or induce cell death. SPIO toxicity is believed to be highly correlated with the cores and coatings. Usually, the SPIO core should have a magnetic responsive component. Some high-magnetic materials such as nickel are easy to be oxidized, thus leading to certain toxicity
A

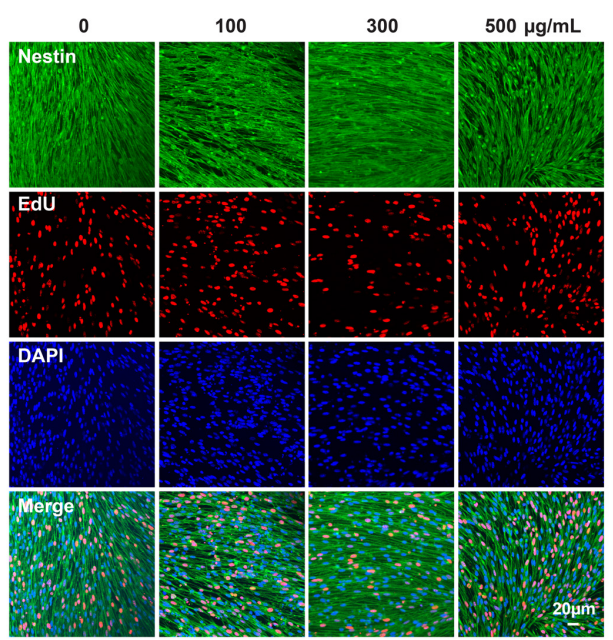

C

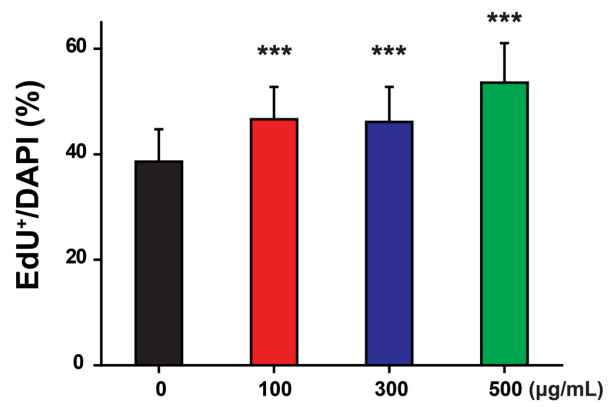

B

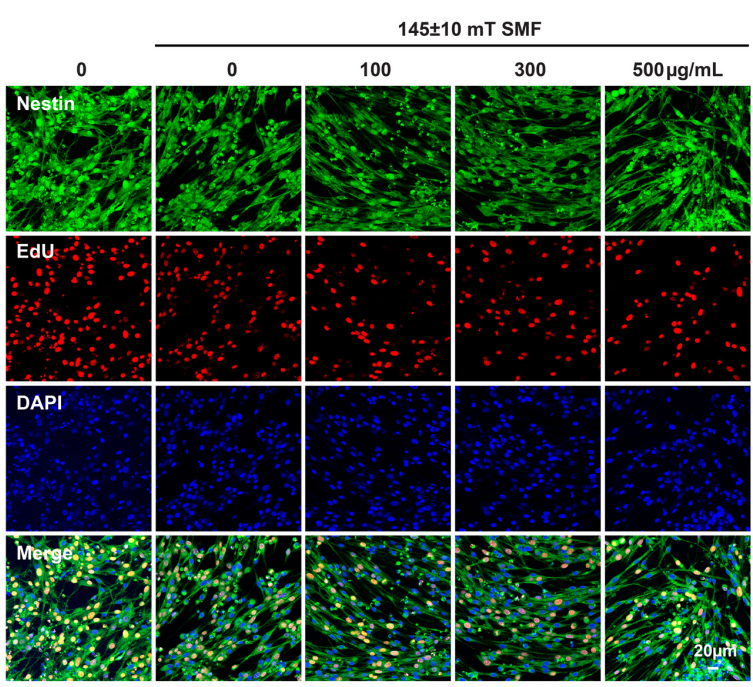

D

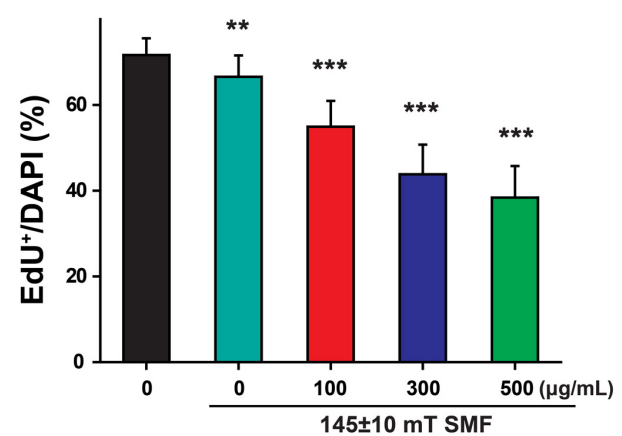

FIGURE 5 | Neural stem cells proliferation was measured by EdU labeling. NSCs were cultured with indicated concentrations of SPIO (100, 300, and 500 $\mu \mathrm{g} / \mathrm{ml})$ with or without $145 \pm 10 \mathrm{SMF}$ for 3 days. EdU was added to the culture from day 2 to day 3 . Representative images for EdU staining in (A) control group and (B) $145 \pm 10 \mathrm{mT}$ SMF group with or without SPIO treatment at indicated concentrations (100, 300, and $500 \mu \mathrm{g} / \mathrm{ml})$. The ratio of EdU + /DAPI was shown in (C,D), respectively. Data are presented as mean $\pm \mathrm{SD},{ }^{* \star} p<0.01,{ }^{* \star *} p<0.001$. 

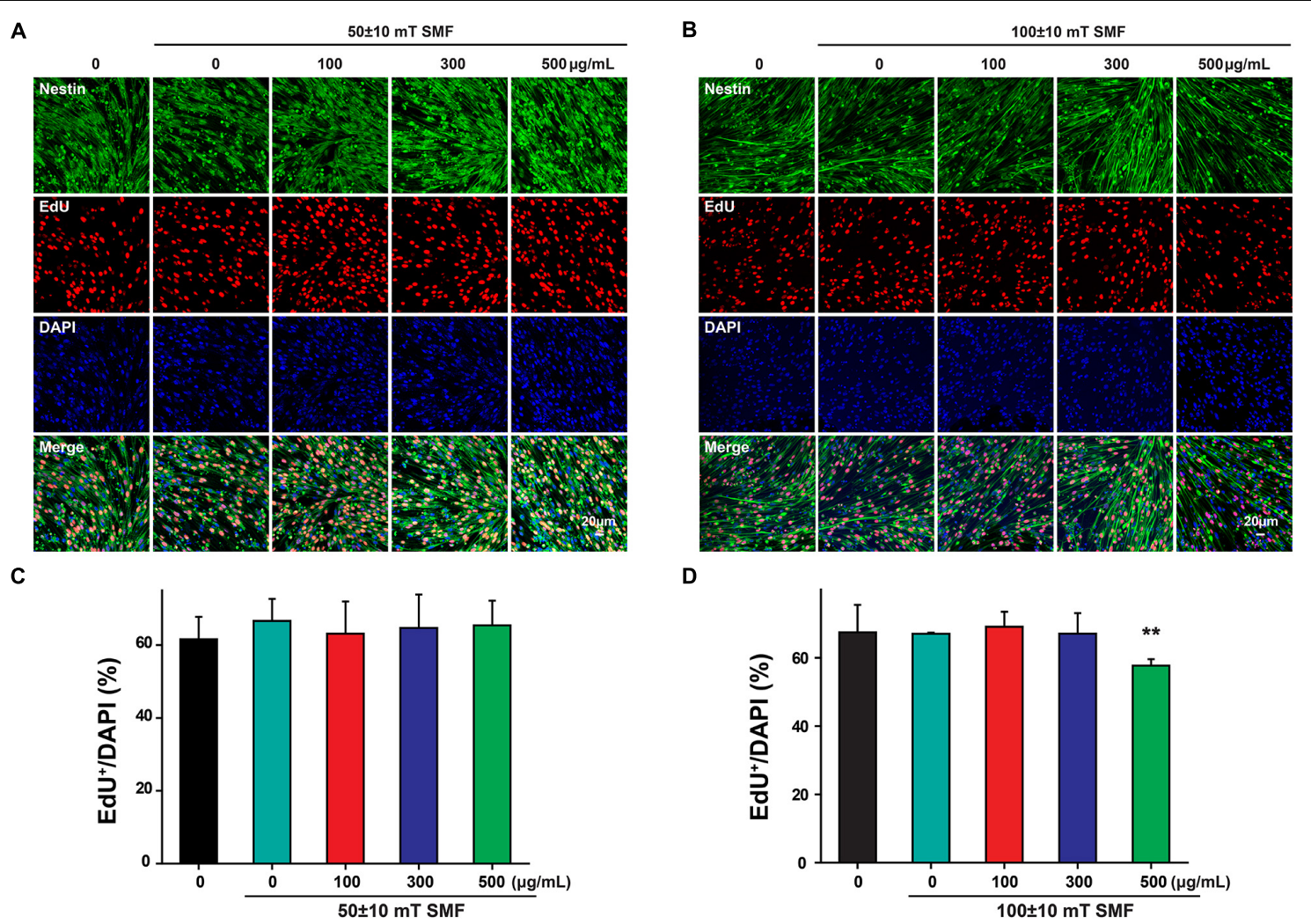

D

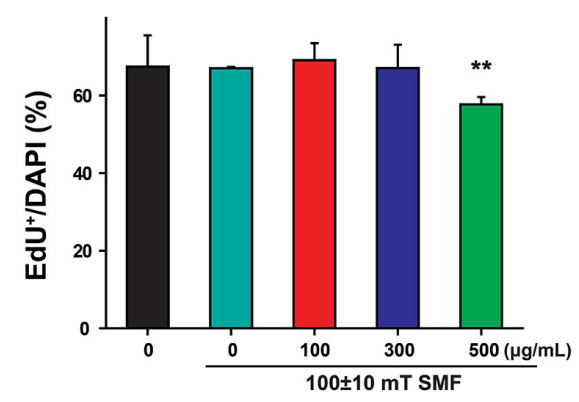

FIGURE 6 | Neural stem cells proliferation was measured by EdU labeling. NSCs were cultured with indicated concentrations of SPIO (100, 300 , and 500 $\mu \mathrm{g} / \mathrm{ml}$ ) with or without SMF for 3 days. EdU was added to the culture from day 2 to day 3 . Representative images for EdU staining in (A) $50 \pm 10 \mathrm{mT}$ group and (B) $100 \pm 10 \mathrm{mT} \mathrm{SMF}$ group with or without SPIO treatment at indicated concentrations (100, 300, and 500 $\mu \mathrm{g} / \mathrm{ml})$. The ratio of EdU + /DAPI was shown in (C,D), respectively. Data are presented as mean $\pm \mathrm{SD},{ }^{\star \star} p<0.01$.

(Tartaj and Serna, 2003; Mahmoudi et al., 2011). The main iron oxides, hematite $\left(\alpha-\mathrm{Fe}_{2} \mathrm{O}_{3}\right)$, maghemite $\left(\gamma-\mathrm{Fe}_{2} \mathrm{O}_{3}\right)$, and magnetite $\left(\mathrm{Fe}_{3} \mathrm{O}_{4}\right)$ are superparamagnetic and also have good biocompatibility. In this study, SPIOs were prepared by an alternating-current magnetic field (ACMF)-induced internalheat mode that was described previously (Chen et al., 2016). The SPIOs synthesized in this study were composed of a $\gamma-\mathrm{Fe}_{2} \mathrm{O}_{3}$ core and PSC shell. This type of SPIOs has good biosafety, as evidenced by our results. In addition, size could be a critical factor to determine SPIO cytotoxicity. It is believed that SPIOs with a diameter ranging from 10 to $100 \mathrm{~nm}$ are considered to be optimal for the purpose of systemic administration (Wahajuddin and Arora, 2012). SPIO toxicity was also reported with a particle size within this range. In this study, the SPIO size was within $20-40 \mathrm{~nm}$, and no obvious cytotoxicity was observed at this range.

In summary, we found that SPIOs are a potential regulator for NSC expansion. SPIOs at appropriate concentrations can elevate the proliferation ability of NSCs. In the meantime, our results also indicate that SMF may suppress NSC proliferation at high intensity. In the future, we will make the best effort to uncover the biological effects of SPIOs on NSC behaviors, including migration and differentiation. Also, the detailed mechanisms underlying the observed effects will be explored as well.

\section{DATA AVAILABILITY STATEMENT}

The raw data supporting the conclusions of this article will be made available by the authors, without undue reservation.

\section{ETHICS STATEMENT}

The animal study was reviewed and approved by Southeast University.

\section{AUTHOR CONTRIBUTIONS}

DL, YH, HW, WC, YL, XY, LG, ML, and BC conducted the experiments and analyzed the data. $\mathrm{RC}$ and MT supervised the study and acquired the funding. All authors wrote the manuscript.

\section{FUNDING}

This study was supported by grants from the Major State Basic Research Development Program of China (973 Program) (2017YFA0104303), the National Natural Science Foundation of China (No. 81970883), and the Hefei University Scientific Research and Development Fund (20ZR08ZDA). 


\section{REFERENCES}

Allazetta, S., and Lutolf, M. P. (2015). Stem cell niche engineering through droplet microfluidics. Curr. Opin. Biotechnol. 35, 86-93. doi: 10.1016/j.copbio.2015. 05.003

Benoit, D. S. W., Schwartz, M. P., Durney, A. R., and Anseth, K. S. (2008). Small functional groups for controlled differentiation of hydrogel-encapsulated human mesenchymal stem cells. Nat. Mater. 7, 816-823. doi: 10.1038/ nmat2269

Carletti, B., Piemonte, F., and Rossi, F. (2011). Neuroprotection: the Emerging Concept of Restorative Neural Stem Cell Biology for the Treatment of Neurodegenerative Diseases. Curr. Neuropharmacol. 9, 313-317. doi: 10.2174/ 157015911795596603

Chen, B., Li, Y., Zhang, X. Q., Liu, F., Liu, Y. L., Ji, M., et al. (2016). An efficient synthesis of ferumoxytol induced by alternating-current magnetic field. Mater. Lett. 170, 93-96.

Dalby, M. J., Gadegaard, N., Tare, R., Andar, A., Riehle, M. O., Herzyk, P., et al. (2007). The control of human mesenchymal cell differentiation using nanoscale symmetry and disorder. Nat. Mater. 6, 997-1003. doi: 10.1038/nmat2013

Engler, A. J., Sen, S., Sweeney, H. L., and Discher, D. E. (2006). Matrix elasticity directs stem cell lineage specification. Cell 126, 677-689. doi: 10.1016/j.cell. 2006.06.044

Fanelli, C., Coppola, S., Barone, R., Colussi, C., Gualandi, G., Volpe, P., et al. (1999). Magnetic fields increase cell survival by inhibiting apoptosis via modulation of Ca2+ influx. FASEB J. 13, 95-102. doi: 10.1096/fasebj.13.1.95

Gage, F. H. (2000). Mammalian neural stem cells. Science 287, 1433-1438. doi: $10.1126 /$ science.287.5457.1433

He, X., Knepper, M., Ding, C., Li, J., Castro, S., Siddiqui, M., et al. (2012). Promotion of spinal cord regeneration by neural stem cell-secreted trimerized cell adhesion molecule L1. PLoS One 7:e46223. doi: 10.1371/journal.pone. 0046223

Huang, D. M., Hsiao, J. K., Chen, Y. C., Chien, L. Y., Yao, M., Chen, Y. K., et al. (2009). The promotion of human mesenchymal stem cell proliferation by superparamagnetic iron oxide nanoparticles. Biomaterials 30, 3645-3651. doi: 10.1016/j.biomaterials.2009.03.032

Kang, K. S., Hong, J. M., Kang, J. A., Rhie, J. W., Jeong, Y. H., and Cho, D. W. (2013). Regulation of osteogenic differentiation of human adipose-derived stem cells by controlling electromagnetic field conditions. Exp. Mol. Med. 45:e6. doi: 10.1038/emm.2013.11

Ledda, M., Fioretti, D., Lolli, M. G., Papi, M., Di Gioia, C., Carletti, R., et al. (2020). Biocompatibility assessment of sub-5 $\mathrm{nm}$ silica-coated superparamagnetic iron oxide nanoparticles in human stem cells and in mice for potential application in nanomedicine. Nanoscale 12, 1759-1778. doi: 10.1039/c9nr09683c

Lee, J., Abdeen, A. A., Zhang, D., and Kilian, K. A. (2013). Directing stem cell fate on hydrogel substrates by controlling cell geometry, matrix mechanics and adhesion ligand composition. Biomaterials 34, 8140-8148. doi: 10.1016/j. biomaterials.2013.07.074

Lee, J. H., Jung, M. J., Hwang, Y. H., Lee, Y. J., Lee, S., Lee, D. Y., et al. (2012). Heparin-coated superparamagnetic iron oxide for in vivo MR imaging of human MSCs. Biomaterials 33, 4861-4871. doi: 10.1016/j.biomaterials.2012. 03.035

Madhavan, L., and Collier, T. J. (2010). A synergistic approach for neural repair: cell transplantation and induction of endogenous precursor cell activity. Neuropharmacology 58, 835-844. doi: 10.1016/j.neuropharm.2009.10.005

Mahmoudi, M., Sant, S., Wang, B., Laurent, S., and Sen, T. (2011). Superparamagnetic iron oxide nanoparticles (SPIONs): development, surface modification and applications in chemotherapy. Adv. Drug Deliv. Rev. 63, 24-46. doi: 10.1016/j.addr.2010.05.006

Mathieu, P., Battista, D., Depino, A., Roca, V., Graciarena, M., and Pitossi, F. (2010). The more you have, the less you get: the functional role of inflammation on neuronal differentiation of endogenous and transplanted neural stem cells in the adult brain. J. Neurochem. 112, 1368-1385. doi: 10.1111/j.1471-4159.2009. 06548.x

McMurray, R. J., Gadegaard, N., Tsimbouri, P. M., Burgess, K. V., Mcnamara, L. E., Tare, R., et al. (2011). Nanoscale surfaces for the long-term maintenance of mesenchymal stem cell phenotype and multipotency. Nat. Mater. 10, 637-644. doi: $10.1038 /$ nmat3058

Qiu, Y., Tong, S., Zhang, L., Sakurai, Y., Myers, D. R., Hong, L., et al. (2017). Magnetic forces enable controlled drug delivery by disrupting endothelial cell-cell junctions. Nat. Commun. 8:15594. doi: 10.1038/ncomms15594
Reekmans, K., Praet, J., Daans, J., Reumers, V., Pauwels, P., Van Der Linden, A., et al. (2012). Current challenges for the advancement of neural stem cell biology and transplantation research. Stem Cell Rev. Rep. 8, 262-278.

Riggio, C., Calatayud, M. P., Giannaccini, M., Sanz, B., Torres, T. E., FernandezPacheco, R., et al. (2014). The orientation of the neuronal growth process can be directed via magnetic nanoparticles under an applied magnetic field. Nanomed. Nanotechnol. Biol. Med. 10, 1549-1558. doi: 10.1016/j.nano.2013.12.008

Ross, C. L., Siriwardane, M., Almeida-Porada, G., Porada, C. D., Brink, P., Christ, G. J., et al. (2015). The effect of low-frequency electromagnetic field on human bone marrow stem/progenitor cell differentiation. Stem Cell Res. 15, 96-108. doi: 10.1016/j.scr.2015.04.009

Saha, K., Mei, Y., Reisterer, C. M., Pyzocha, N. K., Yang, J., Muffat, J., et al. (2011). Surface-engineered substrates for improved human pluripotent stem cell culture under fully defined conditions. Proc. Natl. Acad. Sci. U. S. A. 108, 18714-18719. doi: 10.1073/pnas.1114854108

Schafer, R., Kehlbach, R., Muller, M., Bantleon, R., Kluba, T., Ayturan, M., et al. (2009). Labeling of human mesenchymal stromal cells with superparamagnetic iron oxide leads to a decrease in migration capacity and colony formation ability. Cytotherapy 11, 68-78. doi: 10.1080/14653240802666043

Singh, A. V., Dad Ansari, M. H., Dayan, C. B., Giltinan, J., Wang, S., Yu, Y., et al. (2019). Multifunctional magnetic hairbot for untethered osteogenesis, ultrasound contrast imaging and drug delivery. Biomaterials 219:119394. doi: 10.1016/j.biomaterials.2019.119394

Tartaj, P., and Serna, C. J. (2003). Synthesis of monodisperse superparamagnetic Fe/silica nanospherical composites. J. Am. Chem. Soc. 125, 15754-15755.

Wahajuddin, and Arora, S. (2012). Superparamagnetic iron oxide nanoparticles: magnetic nanoplatforms as drug carriers. Int. J. Nanomedicine 7, 3445-3471. doi: 10.2147/IJN.S30320

Wang, Q. W., Chen, B., Cao, M., Sun, J. F., Wu, H., Zhao, P., et al. (2016). Response of MAPK pathway to iron oxide nanoparticles in vitro treatment promotes osteogenic differentiation of hBMSCs. Biomaterials 86, 11-20. doi: 10.1016/j.biomaterials.2016.02.004

Xiao, H. T., Wang, L., and Yu, B. (2015). Superparamagnetic iron oxide promotes osteogenic differentiation of rat adipose-derived stem cells. Int. J. Clin. Exp. Med. 8, 698-705.

Xu, L., Yuan, S., Chen, W., Ma, Y., Luo, Y., Guo, W., et al. (2020). Transplantation and Tracking of the Human Umbilical Cord Mesenchymal Stem Cell Labeled with Superparamagnetic Iron Oxide in Deaf Pigs. Anat. Rec. 303, 494-505. doi: 10.1002/ar.24346

Yim, E. K. F., Darling, E. M., Kulangara, K., Guilak, F., and Leong, K. W. (2010). Nanotopography-induced changes in focal adhesions, cytoskeletal organization, and mechanical properties of human mesenchymal stem cells. Biomaterials 31, 1299-1306. doi: 10.1016/j.biomaterials.2009.10.037

Yoneyama, M., Shiba, T., Hasebe, S., and Ogita, K. (2011). Adult Neurogenesis Is Regulated by Endogenous Factors Produced During Neurodegeneration. J. Pharmacol. Sci. 115, 425-432. doi: 10.1254/jphs.11r02cp

Zhang, R., Li, J., Li, J., and Xie, J. (2014). Efficient In vitro labeling rabbit bone marrow-derived mesenchymal stem cells with SPIO and differentiating into neural-like cells. Mol. Cells 37, 650-655. doi: 10.14348/molcells.2014.0010

Conflict of Interest: The authors declare that the research was conducted in the absence of any commercial or financial relationships that could be construed as a potential conflict of interest.

The reviewer FY declared a shared affiliation, with several of the authors YH, WC, $\mathrm{YL}, \mathrm{XY}, \mathrm{ML}$, and RC to the handling editor at the time of the review.

Publisher's Note: All claims expressed in this article are solely those of the authors and do not necessarily represent those of their affiliated organizations, or those of the publisher, the editors and the reviewers. Any product that may be evaluated in this article, or claim that may be made by its manufacturer, is not guaranteed or endorsed by the publisher.

Copyright (c) $2022 \mathrm{Li}, \mathrm{Hu}$, Wei, Chen, Liu, Yan, Guo, Liao, Chen, Chai and Tang. This is an open-access article distributed under the terms of the Creative Commons Attribution License (CC BY). The use, distribution or reproduction in other forums is permitted, provided the original author(s) and the copyright owner(s) are credited and that the original publication in this journal is cited, in accordance with accepted academic practice. No use, distribution or reproduction is permitted which does not comply with these terms. 